Fullagar, S, O'Brien, W \& Lloyd, K. (in press, 2019) Feminist perspectives on third places. In Dolley, J. \& Bosnan, C. (Eds). Rethinking Third Places: Informal public spaces and community building, Cheltenham, UK: Edward Elgar.

\title{
Chapter 2. Feminist perspectives on third places
}

Simone Fullagar, Wendy O’Brien and Kathy Lloyd

\section{INTRODUCTION}

In this chapter we question the assumption that third places are neutral or inherently 'good' spaces in contemporary urban life. Drawing upon different feminist perspectives we explore how third places are conceptualised and practiced in gendered ways that were rarely considered in the early work of Oldenburg (1999). We draw together literature across the fields of leisure studies, geography and urban planning, and gender studies to consider how women embody third places in different ways and the influence of representations that mediate the gendered experience of the city. As leisure researchers our interests focus on the relationship between leisure practices and the gendered context of third places that can facilitate or constrain women's 'right to the city' (Valentine 1989). At the heart of this approach is a question about how we understand the gendered power relations that shape third places with respect to their historical, sociocultural, political and economic context (Massey 2005). Different feminist theories conceptualise gender inequality and patriarchal power in different ways that offer multiple perspectives on the formation of third places and possibilities for change. We draw upon this diversity to consider the gendered assumptions informing third places, the sociality of third places for women, gendered embodiment and cultural representations as well as the gendered effects of digital technology and more-thanhuman third places.

\section{THE GENDERED FORMATION OF THIRD PLACES}

Feminist geographers, such as Valentine (1989 p. 389), have long argued that 'women's inhibited use and occupation of public place is a spatial expression of patriarchy'. Ortiz Escalante and Sweet (2013) also articulate how both theoretical and everyday conceptualisations of space are deeply shaped by such gender power relations that are supported by a public-private divide while also being male-centred and ethnocentric. It is reinforced by a gender dichotomy of male-female. That is, the "public-private divide is parallel and mutually supported by parochial and conservative understandings that adhere to gender as male and female' (Sweet and Ortiz Escalante 2015 p. 1830). Not only does this dichotomous construction of space position women as 'naturally' occupying the private, domestic sphere of reproduction and care in contrast to men's entitlement to public life, it also obscures the way gender is lived in more complex and intersectional ways. The spatiality of gender relations and identity formation requires us to think about transgender and nonbinary identifications, along with gendered experiences of difference related to class, 
sexuality, culture, age and ability. Through our focus on women's ${ }^{1}$ experience, we take up the question of thinking with difference throughout the chapter as we understand gender to be performative - 'that is, constituting the identity that it is purported to be' (Butler 1990 p. 25). In this sense gender is an aspect of identity and social relations that we 'do' in the enactment of everyday practices, ways of thinking about cities, designing places and theorising about third places.

In thinking about the spatiality of third places we draw upon feminist theorists who think about the relationality of gendered meaning, embodied movement and knowledge production. As Massey argues, 'space does not exist prior to identities/entities and their relations'; rather, 'identities/entities, the relations "between" them, and the spatiality which is part of them, are all co-constitutive' (Massey 2005 p. 10). The gendered meanings of third places are not simply produced through women's individual actions or determined by the structural forces of patriarchial culture and insitutions. Third places are gendered through their embodied spatial practices, everyday interactions and histories that connect with the eonomic forces of global capitalism, the individualising imperatives of advanced liberalism and the persistent problems of social inequity (Massey 1994). The challenge that is evoked by Massey in this quotation involves contesting implicitly masculine assumptions about spatiality and third places, because 'we have inherited an imagination so deeply ingrained that it is often not actively thought' (Massey 2005 p. 17).

In this chapter we argue that Oldenburg's (1999) emphasis on third places in the social infrastructure of cities and the conviviality of public life tended to overlook the complex power relations that entangle gender identities within the sociocultural, political, historical and economic context of leisure practices. We explore the arguments of a number of scholars who have identified the need to move beyond the assumption that leisure cultures performed in third places are necessarily gender inclusive and equitable. For example, Johnson and Samdahl (2005) identified how gay bars can act as a third place for queer identification away from heteronormative judgement, yet they also noted the pervasiveness of misogynistic practices that excluded women. Writing about the revival of roller derby ${ }^{2}$ as a new sport created by women for women, Pavlidis and Fullagar (2014) provide insights into how third places that are created in the name of empowerment can also serve to obscure the emotional and spatial dynamics of inclusion and exclusion between women. Refusing to simply view roller derby as a static, 'bounded' third place, Pavlidis and Fullagar (2014 p. 33) suggest that analyzing 'how the derby body is put into motion, and the affects it generates in relation to other bodies, we offer another way of thinking through the movement of gendered subjectivity as it is imagined, felt and reinvented through sport spaces'.

This way of thinking moves beyond the rather static and disembodied formulation of

\footnotetext{
${ }^{1}$ We use the term women to refer to a gender category that is a matter of self-identification and subject positioning (cis and transgender). We also note the limitations of either or categories of gender for non-binary identifications.

${ }^{2}$ Roller derby has had a revival in the last decade and was started by women with a 'by the skater, for the skater' ethos. As a contact sport derby 'bouts' are played by two teams with five members on roller skates who compete on a flat track. The 'jammer' scores points by lapping the opposing team who seek to block them.
} 
spatiality assumed in Oldenburg's formulation of third places and opens up questions that we will pursue about the gendered flows of power as they regulate women's leisure and create sites of challenge and resistance. Hence, Oldenburg's (1999 p. 24) claim that, 'a place that is a leveler is, by its nature, an inclusive place' requires feminist rethinking in terms of exploring how gendered power works in ways that reveal how third places can never simply be assumed as neutral or essentially 'good'.

\section{THE VALUE OF LEISURE PRACTICES: GENDERED SOCIAL RELATIONSHIPS}

Cities offer a range of third place leisure possibilities for residents and tourists. However, these leisure opportunities are not simply a matter of individual choice, they are often open to some groups and not others (Skeggs 1999). Sites for leisure are highly negotiated material and discursive spaces (Zukin 1995) where only certain citizens are able to exercise power in terms of access, recognition of identity and meaning construction. For women, the representations of space powerfully shape not only if they can access places, but also how they engage with places meant for public and civic pleasure, conviviality and belonging.

According to Johnson and Glover (2013) feminist geographers have argued the manner in which place is differentially gendered, including who owns the place and therefore who can control entry. Studies have identified a wide range of forms of ownership of space from public to private places and private-public places including pubs, bars and cafes that are open to the public yet any patron can be removed at the manager's discretion. However, increasingly, many of these places are being appropriated by the public for leisure activities so that ownership and public-private divisions have become more complex issues. For example, coffee shops and other 'third places' have now become community hubs for social interaction and this is seen to contribute to community well-being (Oldenburg 1999). As Oldenburg (1999) made clear, so-called private places such as restaurants, coffee shops, and hair salons embody places where a sizeable portion of the population now experience community. Often these are the places in which people experience their leisure in public and they are especially important for women. Meaningful positive social interactions have been identified as the precursor for social connections and the vital ingredient that creates a 'Social City' (Kelly et al. 2012). However, the third places chosen for interaction must be safe and transparent places, both physically and socially for women (Fincher and Iveson 2008). It may be the case that as Silverstone (1997) argued suburban culture is a gendered culture, so is the city in ways that often present contradictions in the name of safe sociability. For example, Skeggs (1999) noted that community programmes such as Crimewatch can work to constrain women's movement in the name of keeping them 'safe' in their homes in the suburbs.

Leisure researchers have long been interested in the sociality of third places within and beyond the city, as Yuen and Johnson (2017 p. 296) suggest, '[L]eisure settings, such as curling clubs, farmers' markets, and support groups involving workshops and social activities, have been examined as third places in the leisure literature' (Glover and Parry 2009; Glover et al. 2012; Johnson 2013; Mair 2009). Such places are often presented as gathering spaces where individuals can informally connect with family, friends, or community members. This body of literature also makes clear that such 'free choices' are 
undertaken within a context of multiple constraints, both explicit (e.g. available time, money, access to facilities and programmes) and hidden (e.g. cultural expectations of what is appropriate behaviour). For women in particular, leisure is very much 'constrained or enabled by patterns of work and family circumstances', for example, access to free time, income, social support, and cultural beliefs that work to both reinforce, and also disrupt private-public divisions (Brown et al. 2001 p. 132).

Aitchison (1999) noted, in an early study of women and bingo in Leeds by Dixey and Talbot (1982), the existence of gendered leisure place, the male domination of public leisure place, and the response by women of carving out a spatial sanctuary in the form of the bingo hall. Deem (1986) built on Dixey and Talbot's work by emphasising the differences between women in relation to their access to leisure and control of public leisure place and focused on the difficulties working class women, or women with young children, experienced in gaining access to leisure. For women, social encounters can occur in a range of leisure settings and guises and can be more or less bounded - that is, more or less exclusionary. Peattie (1998) emphasised the value of 'third places' - like coffee shops, community centres, bars, post offices and grocery stores - as outside-work/home sites that could offer familiarity and the opportunity for social encounters, some without cost. Examples of potential third places suggested by Fincher and Iveson (2008) that can accommodate women's financial, safety and social interaction needs include street festivals, public libraries, drop-in centres and community centres.

While these studies of how third places offer women experiences of connection and safety, gender has largely been thought of in an isolated way from other relations of power (ethnicity, class, religion, age, ability, sexuality etc.). One of the limitations in Oldenberg's (1999) work on third places is the privileging of a white, masculine and largely middle class world view that is assumed to be the 'norm' against which other racialised identities and meanings are defined or ignored. The example of pubs as visible third places highlights this point in relation to the normative assumptions about masculinity, heterosexuality and whiteness (also in terms of religions where alcohol is not consumed). In contrast, in their work on the cultural and gendered dimensions of public leisure places, Watson and Ratna (2011) draw upon the conceptual framework of intersectionality that arose out of the work of black feminists on the intensification of oppressive relations related to race, class, gender, ability, age, sexuality (on intersectionality see Cho et al. 2013). While there are ongoing debates about how intersectionality is thought in terms of marginalised and privileged identities, Styhre and Eriksson-Zetterquist (2008 p. 567) argue for a relational understanding wherein 'subject positions are not fixed and unified but fleeting and fluid identities emerging in continuously changing networks of humans, technologies and artefacts'. Watson and Ratna's (2011) study of a Bollywood festival held in a local park in northern England with a South Asian diaspora, provides a useful counterpoint for thinking through the dynamic intersectional relations that shape how a cultural festival and park interconnect as a third place. They offer a means of thinking critically about the historical, political and economic relations that shape leisure within third places as sites of negotiation over the cultural identities of groups and nations (white and South Asian Britishness). Rather than view the park festival as a 'contained' site for leisure enjoyment, they understand the porous boundaries and multiple gender relations that constitute third places as 'part of a dynamic 
interface between dominant discourse that positions British Asian as other and active participation in which minority ethnic identity is publicly expressed and celebrated ... 'There was a female presence, albeit less spectacular and "in-your-face" than the manner in which some young males were behaving' (Watson and Ratna 2011 pp. 77-82). They highlight the complex interrelationships between gendered and racialised experiences within and outside the festival as young women felt both included and also marginal within shifting flows of the space. There is growing attention in research and policy on the role of third places in supporting social cohesion through informal leisure practices (parks, festivals, exhibitions) and convivial everyday relations (on parks see Neal et al. 2015). What is often missing is a more complex appreciation of how intersectional relations play out in gendered ways that often marginalise women's public participation.

\section{THIRD PLACES THAT FACILITATE SOCIAL CONNECTION}

In recent decades, the physical and social settings for creating connected and cohesive populations have been progressively eroded due to more individualised lifestyles and social networks that are not only geographically spread but also increasingly virtual (Lloyd et al. 2016) (see Williams and Kim, Chapter 9 this volume). However, third places, when conceptualised as traditional and non-traditional ways and locales can benefit women beyond initial social interaction to social connection. Son et al. (2010), for example, examined the emergence of social capital in a leisure club for middle-aged and older women and connected these outcomes to issues of individual and community health and well-being. Findings showed that not only did members make friends, interact with the broader community and gain recognition for their volunteer work, they also experienced what could be described as leisure, 'play, dress, fun and laughter' (Son et al. 2010 p. 80). These outcomes were seen to help women resist notions of ageism and give them increased leverage within the broader community. Furthermore, leisure-based volunteer experiences in a local community theatre were found to give older women a sense of personal growth that in turn benefitted the broader community (Burden 2000). These women not only developed performance and production skills, but also gained satisfaction, a sense of freedom and a sense of community. As IsoAhola and Park (1996) explained, beyond the physical benefits of these activities, groups form a critical part of the social 'glue' in that they provide a supportive place for sharing thoughts and feelings.

The physical spaces where community plays out have also been identified as an important aspect of third places. They not only provide the setting for meetings and interactions but also create the characteristics that are essential for people to enter these spaces including access and safety. Cheang (2002) reported on a group of Japanese American older adults in a 'third place', the fast food restaurant they frequented regularly. For this group, sociability and play were central features of their interactions but perhaps more importantly, the older adults' breakfast group created enduring relationships, a sense of community, and followed group norms. In addition, they had developed their own space inside the restaurant through their regular sessions and sense of membership. Outdoor spaces can also provide opportunities to create third places within and beyond the urban milieu. For 
example, Krenichyn (2006 p. 640) reported that some women found one large city park to be a 'socially intimate place and their activities there to be enriched by the presence of others, because the park was a place for bringing family, meeting friends, or encountering strangers on a regular basis'. This was a somewhat surprising finding, given the often heard representations of urban parks as dangerous and fearful places for women. Krenichyn (2006) concluded that these perceptions of trust and community interact with women's perceptions of their own safety and vulnerability in ways that construct third places as desirable or fearful locales.

Despite the central theme of meeting people that is core to the concept of the third place, Adamson and Parker (2006) argued that provision of social infrastructure is essential to mediate spatial experience. Williams and Pocock (2010) examined residents of master planned communities in Australia about the physical (e.g. buildings and facilities) and social infrastructure (e.g. formal groups and networks) provided in their living environment. Most participants indicated that superficial familiarity was facilitated by centralised facilities, recreation areas, community groups and events. However, although women were generally satisfied with these resources, new mothers in particular needed access to services, information and companionship. Importantly this included formal services and informal social groups of other mothers for social connection. In addition, a third place such as a cafe designed to accommodate pram access, a breast feeding area and nappy change facilities is important (Oldenburg and Brissett 1982). Functional and attractive places can not only benefit new mothers and families but also foster informal interaction between women who may not have other avenues of social connection. As Wearing (1995 p. 129) noted, if women 'don't see the city as a viable venue for their leisure, then they will not venture into the spaces from which they feel alienated and so they will not participate in the process of making the place a valued community resource'. It is in this way that 'third places' are particularly important to women's experiences of the city (Oldenburg and Brissett 1982).

The significance of third places for women's engagement in city life has gained greater attention in the political context of 'austerity' measures in the United Kingdom where cuts to local services have severely reduced public leisure provision from libraries, childcare, sport facilities, programmes and parks (Gilmore 2017; Jensen and Tyler 2012). Caddock (2017 pp. 69-70) identifies the effects on, and range of responses by women in different cities:

...austerity is a feminist issue given its direct and disproportionate impact on women and the implicit reinforcement of wider gender roles and norms. While the gendered nature of the cuts is reflected by feminist activism in some localities such as Bristol - where in May 2015 a group of young women organized a march of thousands against austerity (Bristol Post, 2015) - within Nottingham there is a distinct feeling that wider anti-austerity campaigns such as the People's Assembly do not adequately address women's concerns and women therefore do not relate to such activism. In response, women are forming their own community groups to combat the gendered impacts of austerity by providing practical support to women affected by the cuts. 
Third places, such as libraries (see Istvandity et al., Chapter 7 this volume), have been a significant focus of local activism as they are leisure place used more often by women (and their children) and perceived to be largely safe, inclusive spaces. Yet, the meaning of such third places as self-evident sites of 'public good' have been subject to intense political contestation that is bound up with the erosion of the welfare state, individualising responsibility for cultural resources and a fundamental challenge to the equitable provision of public services (Jensen and Tyler 2012). Public parks as different kinds of third places that have been 'freely' available to women are also under threat from the withdrawal of government funds, despite research identifying their value as spaces for cross-cultural interaction (Gilmore 2017). While volunteering has been a commonly identified local solution to the closure of libraries and parks, there are significant problems with the shifting of state responsibilities onto citizens without resourcing. This is particularly the case for women whose labour is more often unpaid. These stark examples illustrate how third places are bound up with economic, political and social forces that profoundly affect opportunities for leisure and social participation for marginalised women who may be lone parents, poor, disabled and further isolated within society. Next we explore the less tangible dimensions of patriarchal power relations in terms of how the masculine 'gaze' on women and their bodies regulates choices, and how women turn that gaze upon themselves in self-limiting (and often self-protecting) ways.

\section{(IN)VISIBLE BODIES AND MEDIATED THIRD PLACES}

Writing almost three decades ago, Wekerle (1980) argued women were 'out of place' in many urban public place, such as cafes and restaurants. Several decades on Flanagan and Viliulis (2011) reiterate that these spaces and places have been constructed to create impediments that render women invisible and align with patriarchal notions of appropriate gender behaviours (Flanagan and Valiulis, 2011 p. xiii). Flanagan and Valiulis (2011 p. xii) also contend that women continue to struggle to 'assert their rightful visibility as urban citizens'. These observations extend to the third places in which women engage in interactions with others and negotiate discourses of masculine norms that render their bodies either invisible or positioned as visible in particular ways. In feminist research and scholarship women's visibility is constituted through the conceptualisation of the male gaze. Through this notion women are positioned as sexualised subjects and the object of male desire (Boyer 2012).

Media and advertising 'representations' in and around third places also work to intensify the gaze through the portrayal of sexualised or gendered images. Rosewarne (2005) argues that these images perpetuate gender roles, with men controlling space and women to be gazed upon within those spaces. These sexualised images convey the notion that women are an 'object of sexual consumption' and hence increases their sense of vulnerability (Rosewarne, 2005 p. 73). Gill (2009) writes that objectification has moved to a new phase in the 'post-feminist' context of neoliberalism where sexual subjectification is taken up as a matter of choice and empowerment (aka 'girl power'). The dramatic rise of 'raunch' culture has reworked the sexualisation of women's bodies in complex and contradictory ways (Evans 
et al. 2010). While seemingly offering a way for women to express agency and challenge their sexualisation, in order to be understood, 'such parodies must draw on, and thus repeat, dominant discourses of female sexuality, including objectification' (Evans et al. 2010 pp. 126-127). As Gill (2009 p. 150) argues this exercise of 'choice' can work as another form of exclusion, with only 'young, white, heterosexual and conventionally attractive' women able to access the empowerment promised. Older women, women of non-white ethnicity, different shapes and sizes, abilities and sexualities entering third places are less likely to feel any sense of ease or comfort within the visual economy of gender.

The rise of consumer culture within global capitalism is positioned as a key site through which women are urged to attain freedom, pleasure and success through exercising their right to consume and interact in coffee shops, pubs, restaurants and shopping centres (Kern 2010). Yet the third places in which women consume, such as restaurants, bars, and coffee shops remain highly gendered. Lone women dining in restaurants during the day are more likely to feel a sense of belonging than those who challenge the gendered order by dining alone at night (Lahad and May 2017). Bars are another place of social segregation where women are often vastly outnumbered by men (Bird and Sokolofski 2005). Bird and Sokolofski (2005 p. 226) also highlight that even in places such as coffee shops that do not provide 'stereotypically 'masculine' symbolism', men can create a masculine domain simply by the manner in which they act. The deference afforded to men works to marginalise and objectify women (Bird and Sokolofski 2005). Bird and Sokolofski (2005) highlight that in certain instances women are able to control spaces in ways that exclude men. However, the instances of this occurring were relatively few, and socio-spatial practices in third places contribute 'to the apparent 'naturalness' of a gendered order that privileges men' (Bird and Sokolofski 2005). Perhaps more importantly any challenge through 'empowerment' is reliant on individuals to enact change, hence broader changes to women's experiences of third places remains mired in a status quo.

For women who are mothers, entering third places presents another range of gendered and material challenges. Boyer and Spinney's (2016) research on mother's journey making with prams highlights the difficulties they encounter as they attempt to move beyond domestic places into public places. Steps, small doorways, lack of lifts and public judgement of motherhood often significantly impede mothers' movements around third places. The notion of the perfect mother, caring appropriately, avoiding risks, adds a further layer of unease when considering how women feel and engage with third places. For example, women must manage their children in cafes and restaurants to ensure that their presence does not negatively impact on other patrons (Lugosi 2012). Management of breastfeeding in places such as pools or coffee shops also creates public unease which marginalises women (Boyer 2012). Interestingly, Fenster (2005) notes that young mothers often engaged with local places such as shopping centres, more intensively than before they became a mother. However, a mother's right to space has the potential to be undermined by the continued sexualisation of women, evidenced by the rise of the 'yummy mummy'.

When women are subject to the gaze of masculine power, looking can create feelings of uneasiness (Boyer 2012), and fear (Pain 2001; Kern 2010). These feelings, and particularly fear of violence, can work to restrict women's movement, in and around third places (Fairchild and Rudman 2008). Areas that may have been frequented by women during the 
day become ordered as male domains at night. In the night-time economy, where darkness, drink spiking, alcohol consumption and women's supposed sexual availability intertwine in expected and unexpected ways (Sheard 2011). Drink spiking, in particular, has led to young women continually monitoring their drinks to ensure their safety and preclude threats of sexual violence (Brooks 2014). In their study of embodied and gendered drinking practices Waitt et al. (2011) argue that young women negotiated a range of contradictory subjectivities. They used the drinking place to assert a sense of belonging, through social relationships with other women, and assert different feminine identities. They also navigated the male gaze and discourses of safety and fear that position them accountable for unwanted attention. However, as Fileborn (2012) notes, women were more likely to blame themselves for unwanted sexual attention in licensed venues. Fairchild and Rudman (2008) also suggest that harassment by strangers in public places generated feelings of self-blame, objectification and humiliation.

In response to their sexualisation, women are asserting their right to be visible in third places in different ways. For example, an offhand comment by a police officer in Canada that women who dress like sluts were more likely to be victims of sexual assault, prompted 'Slutwalks'. These walks have spread from Canada across the globe into cities in the USA, Australia, Sweden and several other countries (Ringrose and Renold 2012). Women, and their supporters, negate notions of victimhood and male violence towards women through placards and forms of dress. Similarly, 'reclaim the night marches' protested violence against women (Staeheli and Martin 2000). Despite these attempts to claim spaces for women's needs within third places 'across time, space, and place the city has remained a patriarchal creation that strives to keep women in public as invisible as possible' (Flanagan and Valiulis 2011 p. xix).

The very materiality of third places has profoundly transformed to become highly mediated by digital technologies in ways that both open up new possibilities for women's agency, and also generate new forms of violence and sexual harassment through various forms of social media (Ringrose and Renold 2012). Exploring how digital leisure practices are gendered and third places are produced through particular platforms, requires analysis of the wider sociocultural context and micropolitics that shape how gender is negotiated in localised ways. Minahan and Cox (2007) have researched the rise of 'stichn' bitch' as an online/off-line formation of women's cyber culture as a third place. Digital technology affords women the opportunity to exchange resources and ideas as well as meet in groups to knit, stitch and talk (Orton-Johnson 2014). Minahan and Cox (2007) argue that desirability of such gendered places is defined in relation to women's negative responses to major political, social and technological changes that are generating a great sense of uncertainty

\section{GENDER RELATIONS AND MORE-THAN-HUMAN THIRD PLACES}

Although Oldenburg (1999) acknowledged the importance of the cityscape in thinking about the way third places connect people spatially (street corners, facilities, indoor/outdoor buildings, parks), he did not explore more deeply how human experience is thoroughly entangled with the non-human (plants, animals, paved surfaces, objects, lighting etc.). We suggest that the conceptualisation of third places could be extended in light of more 
contemporary feminist approaches to thinking about city experiences as visceral, affective and more-than-human (Pink 2011; Sweet and Ortiz Escalante 2015). Waitt's (2014) exploration of young women's experiences of 'sweating' is a revealing example of how city movement, the sensory body and gendered norms are bound together in ways that shape the gendered experience of third places. For many young heterosexual women sweating evoked a visceral 'disgust' in the feminine body and had to be managed and minimised within third places (such as nightclubs and bars) that feature in the night-time economy of desire. In contrast, sweating bodies were somewhat more acceptable in sport or fitness places associated with self-improving health practices and gendered norms about body image.

Coining the term 'emplacement', Pink (2011) offers a different way of conceptualising the spatial assemblage of the city that moves beyond human centred experience and opens up new ways of thinking about how gender relations shape bodies, practices and interrelationships with non-human nature. Emplacement acknowledges the processes through which the self is moved, affected and transformed by intensities that are produced through place-events (Pink 2011). This conceptualisation is useful for thinking through third places as not simply spatial 'containers' within which human action occurs, but rather as performative leisure-events that transform embodied knowing and skill as we move and 'become part of a specific configuration, or ecology, of persons and things' (Pink 2011, p. 344).

An example from our research (Fullagar 2012; Fullagar and Pavlidis 2012) into women's experience of long-distance mass cycling events through city and rural places illustrates this more mobile, embodied and post-human notion of third places. Women's experiences of cycling with 1000 riders in a non-competitive event over nine days was often articulated in terms that forged unique gendered meanings around bike-body configurations; moving at one's own pace - sensory immersion in nature - feelings of safety riding collectively on roads - embodied capacities stretched in supportive context - clean bathrooms - new and renewed friendships - camping options - no cooking. The campsite for the event was assembled each night by volunteers and riders into a mobile third place - creating a sense of emplacement where 'the body itself is simultaneously physically transformed as part of this process' (Pink 2011 p. 347). Emplacement also evokes a sense of temporality that conceptualisations of third places often neglect. Through a different example, we can also think about how the value of non-human nature becomes visible when the spatio-temporality of third places, such as community parkrun events, are threatened with closure and reduce equitable opportunities for women's leisure. Parkrun is a free, regular community running event that successfully engages women of difference ages and abilities. Yet with funding cuts in the UK certain park authorities have tried to implement charges that have been very publicly resisted through social media, though not always successfully. Emplacement is a useful spatio-temporal way of thinking about how gender is implicated in human and nonhuman relations, patterns of inequality relating to access to places (cost, fear), time to engage (women's un/paid labour) and cultural histories of third places that reiterate or challenge normative gender expectations and identities.

\section{CONCLUDING REMARKS}


The third places described by Oldenberg rarely considered how these places were gendered in ways that worked to exclude women or were appropriated by women. Women's right to access spaces in the city, where they might enjoy some of the community and sociality of third places, are constrained by public-private dichotomies that reinforce masculine entitlement to public place. Thinking through the relationality and embodied spatiality of third places allows us to examine more deeply the ways in which masculine privilege is normalised and women are excluded. For example, women's access and use of leisure places are constrained by patterns of work and family, but also by fears of safety, violence and harassment and lack of planning and infrastructure. The sexualisation and objectification of women also works to constrain how women experience third places as pleasurable or fearful sites of interaction. Powerful gender discourses work to shape how women may feel a sense of uneasiness and discomfort that hinders any sense of 'good' or social connection they may feel in such places. In addition, austerity measures that have seen a reduction in public leisure facilities, programmes and parks, and an emphasis on individualism, do little to create safe places where women can experience a sense of community.

Yet a body of feminist work highlights how women rework and reframe these places so they may enjoy them in ways not thought about in Oldenberg's conceptualisation. For example, Oldenberg's work also did not explore the materiality and entanglements of the human and non-human that affect women's experience of third places. Immersion in nature, interacting with various surfaces, plants, animals and lighting allow us to think through the material and embodied dimensions of third places. As we have suggested, Pink's (2011) notion of 'emplacement' offers a way to consider how bodies are transformed through various spatial and place-related interactions. Non-competitive events such as long distance mass cycling, where spatio-temporal boundaries are more fluid, allowed women to feel a sense of connection to both other women and their surroundings. Emplacement also makes visible the connections between spatio-temporality and non-human nature through community parkruns, where women of different ages and abilities can enjoy their own embodiment within a collectively oriented experience.

Together these observations are suggestive for re-thinking women's continued and inequitable access to third places. Issues such as the continued sexualisation of women through various media, including social media, create the context for the objectification of women. Changes need to occur in relation to how women are portrayed through these media, with regulation and legislation required to change stereotypical representations and online harassment. There have been recent changes in Britain with the Advertising Standards Authority introducing new regulatory standards to reduce gender stereotyping in advertisements; no longer will women be subjected to offensive commercial images that reverberate across multiple third places (such as the 'are you beach body ready?' adverts on billboards, television, social media). Similarly legislation needs to address what occurs when women are harassed or threatened with violence, and how women are dealt with when they report these issues. With the rise of violence against women, it is important that policies that have a role in prevention (urban planning, media regulation, community provision) are informed by feminist research that addresses the issues that have led to its increase. While 'reclaim the night marches' provide a forum for women to protest and raise awareness, 
creating cities as safer places for women through planning and infrastructure are important considerations. Poor lighting, ill-considered plantings, lack of security in and around transport contribute to gendered risk for women (see Holden, Chapter 6 this volume). This in turn can affect how women participate in the night-time economy through third places such as bars and nightclubs, interact with their surroundings and where they experience shame and humiliation when harassed. Recognising the gendered impact of austerity measures on the provision of leisure places for the facilitation of social relations and cross-cultural interaction is a challenge for policy makers a different levels to address in relation to further marginalisation and isolation that is occurring in many communities. Despite Oldenberg's contention that third places are inherently 'good' much work is still needed to create places in contemporary life that allow different women to exercise their right to the city.

\section{REFERENCES}

Adamson, L. and G. Parker (2006), "There's more to life than just walking": older women's ways of staying healthy and happy', Journal of Aging and Physical Activity, 14, 380-391. Aitchison, C. (1999), 'New cultural geographies: the spatiality of leisure, gender and sexuality', Leisure Studies, 18(1), 19-39.

Bird, S. and L. Sokolofski (2005), 'Gendered socio-spatial practices in public eating and drinking establishments in the Midwest United States', Gender, Place and Culture, 12 (2), 213-230.

Boyer, K. (2012), 'Affect, corporeality and limits of belonging: breastfeeding in public in the contemporary UK', Health and Place, 18, 552-560.

Boyer, K. and J. Spinney (2016), 'Motherhood, mobility and materiality: material entanglements, journey-making and the process of "becoming a mother", Environment and Planning D: Society and Space, 34 (6), 1113-1131.

Brooks, O. (2014), 'Interpreting young women's accounts of drink spiking: the need for a gendered understanding of the fear and reality of sexual violence', Sociology, 48 (2), 300316.

Brown, P., Brown, W., Miller, Y. and V. Hansen (2001), 'Perceived constraints and social support for active leisure among mothers with young children', Leisure Sciences, 23, 131144.

Burden, J. (2000), 'Community building, volunteering and action research', Loisir et Societe/Society and Leisure, 23, 353-370.

Butler, J. (1990), Gender Trouble: Feminism and the Subversion of Identity. New York: Routledge.

Caddock, E. (2017), 'Caring about and for the cuts: a case study of the gendered dimension of austerity and anti-austerity activism', Gender, Work and Organization, 24 (1), 69-82.

Cheang, M. (2002), 'Older adults' frequent visits to a fast-food restaurant: nonobligatory social interaction and the significant of play in the "third space", Journal of Aging Studies, 16, 303-321.

Cho, S., Crenshaw, K.W. and L. McCall (2013), 'Toward a field of intersectionality studies: theory, applications, and praxis', Signs: Journal of Women in Culture and Society, 38 (4), 785-810. 
Deem, R. (1986), All Work and no Play? The Sociology of Women and Leisure. Milton Keynes: Open University Press.

Dixey, R. and M. Talbot (1982), Women, Leisure and Bingo. Leeds: Trinity and All Saints' College.

Evans, A., Riley, S. and A. Shankar (2010), 'Technologies of sexiness: theorizing women's engagement in the sexualisation of culture', Feminism and Psychology, 20 (1), 114-131.

Fairchild, K. and L. Rudman (2008), 'Everyday stranger harassment and women's objectification', Social Justice Research, 21, 338-357.

Fenster, T. (2005), 'The right to the gendered city: different formations of belonging in everyday life', Journal of Gender Studies, 14 (3), 217-231.

Fileborn, B. (2012), 'Sex and the city: exploring young women's perception and experiences of unwanted sexual attention in licensed venues', Current Issues in Criminal Justice, 24 (2), 241-260.

Fincher, R. and K. Iveson (2008), Planning and Diversity in the City: Redistribution, Recognition and Encounter. New York: Palgrave Macmillan.

Flanagan, M. and M. Valiulis (2011), 'Introduction: gender and the city: the awful being of invisibility', Frontiers, 32 (1), xiii-xx.

Fullagar, S. (2012), 'Gendered cultures of slow travel: women's cycle touring as an alternative hedonism', in S. Fullagar, K. Markwell and E. Wilson (eds), Slow Tourism: Experiences and Mobilities. Bristol: Channel View, pp. 99-112.

Fullagar, S. and A. Pavlidis (2012), “It's all about the journey": women and cycling events', International Journal of Event and Festival Management, 3(2), 149-170.

Gill, R. (2009), 'Beyond the "sexualization of culture" thesis: an intersectional analysis of "Sixpacks", "Midriffs" and "Hot Lesbians" in advertising', Sexualities, 12 (2), 137-160.

Gilmore, A. (2017), 'The park and the commons: vernacular spaces for everyday participation and cultural value', Cultural Trends, 24 (1), 34-46.

Glover, T.D. and D.C. Parry (2009), 'A third place in the everyday lives of people living with cancer: functions of Gilda's Club of Greater Toronto', Health and Place, 15, 97-106.

Glover, T.D., Parry, D.C. and C.M. Mulcahy (2012), 'At once liberating and exclusionary? A Lefebvrean analysis of Gilda's Club of Toronto', Leisure Studies, 32 (5), 1-20.

Iso-Ahola, S.E. and C.J. Park (1996), 'Leisure-related social support and self-determination as buffers of stress-illness relationship', Journal of Leisure Research, 28(3), 169-187.

Jensen, T. and I. Tyler (2012), 'Austerity parenting,' Studies in the Maternal, 4 (2).

http://doi.org/10.16995/sim.34.

Johnson, A.J. (2013), “It's more than a shopping trip": leisure and consumption in a farmers' market', Annals of Leisure Research, 16 (4), 1-17.

Johnson, A.J. and T.D. Glover (2013), 'Understanding urban public space in a leisure context', Leisure Sciences, 35 (2), 190-197.

Johnson, C.W. and D.M. Samdahl (2005), "The night they took over": misogyny in a country-western gay bar', Leisure Sciences, 27 (4), 331-348.

Kelly, J-F., Breadon, P., Davis, C., Hunter, A., Mares, P., Mullerworth, D. and B. Weidmann (2012), Social Cities. Melbourne: Gratton Institute.

Kern, L. (2010), 'Selling the "scary city": gendering freedom, fear and condominium development in the neoliberal city', Social and Cultural Geography, 11 (3), 209-230. 
Krenichyn, K. (2006), "“The only place to go and be in the city": women talk about exercise, being outdoors, and the meanings of a large urban park', Health and Place, 12, 631-643.

Lahad, K. and V. May (2017), 'Just one? Solo dining, gender and temporal belonging in public spaces', Sociological Research Online, 22 (2), 1-11.

Lloyd, K., Fullagar, S. and S. Reid (2016), "Where is the "social" in constructions of "liveability"? Exploring community, social interaction and social cohesion in changing urban environments'. Urban Policy and Research, doi: 10.1080/08111146.2015.1118374.

Lugosi, P. (2012), 'Women, children and hospitable spaces', The Hospitality Review, 12 (1), $31-38$.

Mair, H. (2009), 'Club life: third place and shared leisure in rural Canada', Leisure Sciences, 31 (5), 450-465.

Massey, D. (1994), Space, Place and Gender. Cambridge: Polity Press.

Massey, D. (2005), For Space. London: Sage.

Minahan, S. and J.W. Cox (2007), 'Stitch'nBitch', Journal of Material Culture, 12 (1), 5-21.

Neal, S., Bennett, K., Jones, H., Cochrane, A. and G. Mohan (2015), 'Multiculture and public parks: researching super-diversity and attachment in public green space', Population, Space and Place, 21(5), 463-475.

Oldenburg, R. (1999), Great Good Place: Cafes, Coffee Shops, Bookstores, Bars, Hair Salons and Other Hangouts at the Heart of Community. New York; Marlow \& Company. Oldenburg, R. and D. Brissett (1982), 'The third place', Qualitative Sociology, 5(4), 265284.

Ortiz Escalante, S. and E. Sweet (2013), 'Migrant women's safety: framing, policies and practice', in C. Whitzman, C. Legacy, C. Andrew, F. Klodawsky, M. Shaw and K. Viswanath (eds), Building Inclusive Cities: women's Safety and the Right to the City. London; New York: Routledge, pp. 53-72.

Orton-Johnson, K. (2014), 'Knit, purl and upload: new technologies, digital mediations and the experience of leisure', Leisure Studies, 33 (3), 305-321.

Pain, R. (2001), 'Gender, race, age and fear in the city', Urban Studies, 38 (5-6), 899-913. Pavlidis, A. and S. Fullagar (2014), Sport, Gender and Power: The Rise of Roller Derby. Farnham: Ashgate.

Peattie, L. (1998), 'Convivial cities', in M. Douglass and J. Friedmann (eds), Cities for Citizens. Chichester: John Wiley \& Sons, pp. 247-253.

Pink, S. (2011), 'From embodiment to emplacement: re-thinking competing bodies, senses and spatialities,' Sport, Education and Society, 16 (3), 343-355.

Ringrose, J. and E. Renold (2012), 'Slut-shaming, girl power and "sexualisation": thinking through the politics of the international SlutWalks with teen girls', Gender and Education, 24 (3), 333-343.

Rosewarne, L. (2005), 'The men's gallery: outdoor advertising and public space: gender, fear, and feminism', Women's Studies International Forum, 28, 67-87.

Sheard, L. (2011), "“Anything could have happened": women, the night-time economy, alcohol and drink-spiking', Sociology, 45 (4), 619-633.

Silverstone, R. (ed.) (1997), Visions of Suburbia. London: Routledge.

Skeggs, B. (1999), 'Matter out of place: visibility and sexualities in leisure spaces', Leisure Studies, 18 (3), 213-232. 
Son, J., Yarnel, C. and D. Kerstetter (2010), 'Engendering social capital through a leisure club for middle-aged and older women: implications for individual and community health and well-being', Leisure Studies, 29 (1), 67-83.

Staeheli, L.A. and P.M. Martin (2000), 'Spaces for feminism in geography', The Annals of the American Academy of Political and Social Science, 571 (1), 135-150.

Styhre, A. and U. Eriksson-Zetterquist (2008), 'Thinking the multiple in gender and diversity studies: examining the concept of intersectionality', Gender in Management: An International Journal, 23 (8), 567-582.

Sweet, E.L. and S. Ortiz Escalante (2015), 'Bringing bodies into planning: visceral methods, fear and gender violence', Urban Studies, 52 (10), 1826-1845.

Valentine, G. (1989), 'The geography of women's fear', Area, 21, 385-390.

Waitt, G. (2014). 'Bodies that sweat: the affective responses of young women in Wollongong, New South Wales, Australia', Gender, Place and Culture, 21 (6), 666-682. Waitt, G., Jessop, L. and A. Gorman-Murray (2011), "“The guys in there just expect to be laid": embodied and gendered socio-spatial practices of a "night out" in Wollongong, Australia', Gender Place and Culture, 18 (2), 255-275.

Watson, B. and A. Ratna (2011), 'Bollywood in the park: thinking intersectionally about public leisure space', Leisure/Loisir, 35 (1), 71-86.

Wekerle, G. (1980), 'Women in the urban environment', Signs, 5 (3), S188-S214.

Wearing, B. (1995), Leisure and Feminist Theory. London: Sage.

Williams, P. and B. Pocock (2010), 'Building “community” for different stages of life: physical and social infrastructure in master planned communities', Community, Work and Family, 13 (1), 71-87.

Yuen, F. and A.A.J. Johnson (2017), 'Leisure spaces, community, and third places', Leisure Sciences, 39 (3), 295-303.

Zukin, S. (1995), The Culture of Cities. Oxford: Sage. 